\title{
Dinamika Sosial Budaya Masyarakat Pesisir Panarukan, (Studi Pengelolaan Kerajinan Kayu Di Desa Kilensari)
}

\section{Socio-Cultural Dynamics of Coastal Communities (Case Study; Management of Wood Crafts in Kilensari Village, Panarukan)}

\author{
Dimas Imaniar ${ }^{1 *}$, Yudistira Harisandi ${ }^{2}$ \\ ${ }^{1}$ Dosen FISIP Universitas 17 Agustus 1945 Banyuwangi \\ ${ }^{2}$ Dosen Fakultas Ekonomi Universitas Abdurachman Saleh Situbondo \\ Corresponding Author; dimasimaniars@gmail.com
}

Submited: 26 June 2021 Revised: 09 July 2021 Accepted: 22 July 2021 Publish: 31 July 2021

\begin{abstract}
Abstrak
Tidak ada masyarakat yang tidak mengalami perubahan. Begitu juga dengan masyarakat yang berada di Desa Kilensari Kecamatan Panarukan Kabupaten Situbondo. Seiring perkembangan zaman, masyarakat desa Kilensari mulai berdinamika. Sehingga memunculkan pertanyaan 1) Apa saja aspekaspek yang mengalami perubahan sosial budaya pada aktivitas masyarakat pesisir desa Kilensari? Lalu, faktor-faktor apa saja yang mendorong terjadinya perubahan tersebut?. Metode penelitian yang digunakan adalah kualitatif deskriptif. Pemilihan lokasi di Desa Kilensari Kecamatan Panarukan Kabupaten Situbondo karena lokasi ini merupakan kampong nelayan terbesar di Kabupaten Situbondo dan terdapat tugu 1000 kilometer jalan raya pantura. Subjek penelitian terdiri dari kepala Desa, tokoh masyarakat, pengusaha kerajinan kayu. Teknik Pengumpulan Data berupa observasi, dan wawancara mendalam. Teknik pengambilan sampel yakni purposive sampling. Berdasarkan hasil penelitian, dapat diketahui aspek-aspek yang mengalami perubahan dalam aktivitas pengelolaan kerajinan kayu adalah aspek pengetahuan, aspek kepercayaan, aspek sosial budaya, dan aspek sistem ekonomi. Sedangkan faktorfaktor yang mendorong terjadinya perubahan adalah kontak dengan budaya lain, ketidakpuasan masyarakat terhadap bidang-bidang kehidupan tertentu, orientasi masa depan dan nilai bahwa manusia harus senantiasa berikhtiar untuk memperbaiki hidupnya.

Kata kunci: perubahan, sosial, budaya, kerajinan kayu.
\end{abstract}

\section{Abstract}

There is no society that does not experience change. Likewise with the people in Kilensari Village, Panarukan District, Situbondo Regency. Along with the times, the people of Kilensari Village began to be dynamic. This raises the question 1) What are the aspects that have experienced socio-cultural changes in the activities of the coastal community of Kilensari village? So, what are the factors driving this change? The research method used is descriptive qualitative. The location was chosen in Kilensari Village, Panarukan Subdistrict, Situbondo Regency because this location is the largest fishing village in Situbondo Regency and there is a $1000 \mathrm{~km}$ long monument on the north coast highway. The research subjects consisted of village heads, community leaders, wood crafts entrepreneurs. Data collection techniques in the form of observation, and in-depth interviews. The sampling technique is purposive sampling. Based on the results of the study, it can be seen that the aspects that experience changes in the management of wood crafts are aspects of knowledge, aspects of trust, aspects of socio-culture, and aspects of the economic system. While the factors that encourage change are contact with other cultures, people's dissatisfaction with certain areas of life, future orientation, and the value that humans must always try to improve their lives.

Keywords: change, social, culture, woodworking.

\section{PENDAHULUAN}

Indonesia adalah bangsa yang

besar, yang kaya akan budaya. Hilden

Gert menyebutkan bahwa wilayah

Indonesia ini terdiri dari beribu-ribu pulau yang didiami oleh beranekaragam suku bangsa yang merupakan golongan etnik dan mengunakan lebih kurang 250 bahasa daerah serta memiliki berbagai 
kepercayaan dan kebudayaan yang beranekaragam (Nasikun, 1974). Selain kaya akan budaya, Indonesia juga memiliki kekayaan alam yang berlimpah. Dimana tiap-tiap daerah memiliki ciri khas hasil alam yang menjadi ikon sebuah kota, misalnya Kota Malang terkenal dengan buah Apelnya, Kota Palembang dengan buah Dukunya, Kalimantan dengan Duriannya, dan lain sebagainya, begitu juga dengan Situbondo yang terkenal dengan kerajinan kayu.

Berjarak sekitar 15 Kilometer dari pusat kota Situbondo. Terdapat sebuah Desa yang bernama Kilensari yakni sebuah desa atau kampung istilah masyarakat setempat, yang berada di pesisir utara pulau Jawa tepatnya di Kecamatan Panarukan Kabupaten Situbondo, Desa Kilensari Kecamatan Panarukan adalah wilayah yang didominasi oleh pesisir dengan topografi dataran rendah. Berada pada ketinggian tanah antara 5-7 meter dari permukaan laut. Luas desa Kilensari ini diperkirakan sekitar 15.752 hektar dengan rincian 600 hektar pemukiman masyarakat, 4.000 hektar pemukiman pesisir, 2.500 hektar wilayah industri, 3.120 hektar taman nasional danau zamrud dan jumlah hutan yang diperkirakan lebih kurang sebanyak 5.532 hektar (Kantor Desa Kilensari, 2017). Desa Kilensari memiliki luasan 4,98 $\mathrm{km}^{2}$. Sebagian besar Desa Kilensari merupakan kawasan pesisir pantai berada di ketinggian $3 \mathrm{~m}$ di atas permukaan laut dan jumlah penduduk 14.785 jiwa dengan mayoritasnya adalah suku Madura yang bekerja sebagai Nelayan. Potensi desa yang dapat dikaji sebagian besar yakni bidang pertanian yakni Tanaman Tebu, Padi, Jagung. Bidang kewirausahaan yakni Souvenir dari kerang, Souvenir dari kayu, Kerupuk ikan, Fillet ikan berbumbu. Bidang Perikanan yakni Tambak, Nelayan.

\section{Desa Kilensari Kecamatan} Panarukan Kabupaten Situbondo memiliki 8 dusun diantaranya Pesisir Utara, Pesisir Tengah, Peisisr Selatan, Tanah Anyar, Somangkaan, Bataan, Kilen Selatan, Karangsari. Desa ini merupakan desa yang terdekat dengan wilayah kota dan diberi keindahan alam pesisir yang cukup menabjubkan. Sebagian besar dusun ini memiliki kondisi masyarakat yang bermata pencaharian sebagai nelayan, pengrajin, petani, buruh tani dan peternak. Desa Kilensari adalah salah satu desa yang terletak di Kecamatan Panarukan 
Kabupaten Situbondo. Desa Kilensari memiliki potensi ekonomi yang sangat tinggi, hal ini didukung dengan adanya Pengrajin industri rumah tangga sebanyak 49 jiwa (2010), dan pengusaha kecil, menengah sebanyak 201 jiwa (2010). Potensi yang banyak dilirik konsumen salah satunya adalah adanya kerajinan kerang dan papan selancar. banyak sekali koleksi kerajinan yang berbahan dasar dari kerang.

Masyarakat adalah orang yang hidup bersama yang menghasilkan kebudayan. Dengan demikian tanpa adanya masyarakat sebagai wadah tumbuh kembangnya budaya maka kebudayaan tidak akan ada. Menurut Koentjaraningrat, unsur-unsur kebudayaan adalah (a) peralatan dan perlengkapan hidup manusia seharihari; (b) sistem mata pencaharian dan sistem ekonomi; (c) sistem kemasyarakatan; (d) bahasa sebagai media komunikasi, bahasa lisan dan tulisan; (e) ilmu pengetahuan dan kesenian dan (f) sistem religi (Abidin dan Saebani, 2014). Kehidupan manusia akan selalu mengalami perubahan, tidak ada masya rakat yang benar-benar statis. Sebab kehidupan sosial adalah dinamis (Setiadi dan Kolip, 2011). Kehidupan adalah gerakan dan perubahan, maka bila berhenti berarti tidak ada lagi kehidupan melainkan merupakan suatu keadaan yang sama sekali berbeda yang dsebut ketiadaan atau kematian. (Sztompka, 2017). Perubahanperubahan itu dapat berupa mencolok, ada pula yang berjalan sangat cepat bahkan ada pula yang berjalan sangat lambat (Soemardjan dan Soemardi, 1974).

Berbicara masalah lingkungan, paling tidak dikenal dua konsep tentang lingkungan yaitu; geofisik dan biofisik. Contoh geofisik misalnya; air, tanah, batu-batuan dan sebagainya. Sedangkan biofisik termasuk di dalamnya seperti: tumbuh-tumbuhan, jasad renik, hewan dan manusia itu sendiri. Dari dua konsep lingkungan itu, manusia adalah sentral dari seluruh ritme kehidupan alam ini, dimana manusia mampu mengontrol, merubah dan mempertahankan lingkunga nnya (baik geofisik maupun biofisik) untuk kepentingan hidupnya. Oleh sebab itu, untuk memahami hubungan timbal balik antara manusia dan lingkungannya itu maka harus selalu melihat dari segi kepentingan manusia yang hidup di dalam lingkungan tertentu itu. artinya, bahwa manusia itu hidupnya sangat 
terkait dan dipengaruhi oleh lingkungan dan faktor-faktor lain yang cukup dominan yang memberi arah dan pedoman bagi manusai untuk berperilaku (Hidir, 2009).

Berdasarkan latar belakang di atas maka masalah yang dapat dirumuskan dalam penelitian ini adalah: 1) Apa saja aspek-aspek yang mengalami perubahan sosial budaya pada aktivitas penegelolaan kerajinan kayu di desa Kilensari? Selanjutnya 2) faktor-faktor apa saja yang mendorong terjadinya perubahan pada aktivitas pengelolaan kerajinan kayu tersebut?

\section{METODE PENELITIAN}

Metode penelitian yang digunakan adalah secara kualitatif deskriptif melalui reduksi data, penyajian data dan pengambilan kesimpulan dengan pendekatan fenomenologi dimana peneliti akan melakukan wawancara mendalam yang kemudian hasilnya akan diolah dan interpretasikan untuk dianalisis lebih lanjut dengan menggunakan perspekstif sosiologis. Lokasi Penelitian ditetapkan di Desa Kilensari Kecamatan Panarukan Kabupaten Situbondo karena lokasi ini terdapatnya produk kerajinan berbahan baku dari kayu. Subjek penelitian terdiri dari tokoh masyarakat, pemilik usaha kerajinan kayu dan pemanjat kepala desa.

Teknik Pengumpulan Data berupa observasi, selanjutnya melakukan wawancara dengan key informan ynng mengetahui seluk beluk usaha kerajinan kayu. Teknik pengambilan sampel yakni purposve sampling. Informasi dan data awal yang diperoleh kemudian dikonfimasi dengan informan lainnya sehingga keabsahan data dan informasi dapat dipertanggung jawabkan kebenarannya.

\section{HASIL PENELITIAN}

Perubahan Sosial Budaya dalam Aktivitas Pengelolaan Kerajinan Kayu di Desa Kilensari merangkum pemikiran Sztompka (2017) jika ingin mengakaji masalah perubahan, maka ada hal-hal yang perlu diamati, apakah memang ada hal yang berubah, lalu bagaimana perubahan itu dari suatu jangka waktu dengan waktu yang lainnya, dan perubahan itu tentu saja pada sistem sosial yang sama. Ada tiga hal yang mendasari perubahan sosial yakni apakah terdapat hal-hal yang membedakan.

Dalam penelitian ini ditemukan bahwa aktivitas masyarakat pesisir Desa Kilensari sebagai nelayan mengalami perubahan. Waktu perubahahan dilihat 
sebelum tahun 2002 dimana masyarakat masih melakukan usaha menangkap ikan atau sebagai nelayan. Lalu, mulai tahun 2002 sampai sekarang 2021, kegiatan sebagai nelayan sudah mulai sedikit dikesampingkan. Pra dan pasca tahun 2002 inilah telah terlihat beberapa perbedaan pada aktivitas usaha mengelola kerajinan kayu oleh masyarakat desa Kilensari tersebut. Menurut Kluckhon ada 4 kebudayaan yang bersifat universal yakni pertama, yang mencakup aspek pengetahuan, kedua terkait aspek aspek kepercayaan, ketiga adalah aspek sosial budaya, keempat aspek sosial budaya dalam sistem ekonomi misalnya mata pencaharian dan sistem ekonomi masyarakat (Soekanto, 2013). Berikut beberapa aspek yang mengalami perubahan dalam aktivitas usaha mengelola kerajinan kayu di desa Kilensari.

\section{Aspek Pengetahuan}

Dalam usaha mengelola kerajinan kayu, aktivitas mengelola kerajinan kayu dilakukan pada saat musim ikan di laut mulai minim,sekitar bulan Agustus-Maret atau pada saat bulan purnama. Hal ini dilakukan karena masyarakat mengalami penurunan pendapatan ekonomi pada waktu tersebut. Namun, saat sekarang atau pasca tahun 2002 masyarakat daerah pesisir desa Kilensari banyak beralih usaha dari sebagai nelayan menjadi pengusaha kerajinan kayu. Sehingga hasilnya dapat dinikmati secara terus menerus dan sangat membantu perekonomian para nelayan.

\section{Aspek Kepercayaan}

Sesuai dengan hasil penelitian secara sosial pola dan tradisi serta bentuk kepercayaan yang secara permanen pada masyarakat desa Kilensari merupakan bentuk endapan sosial yang diwariskan oleh nenek moyang secara turun-temurun yang sampai saat ini masih tetap dipertahankan dan dipercayai dari generasi ke generasi terutama dalam kehidupan melaut. Laut dan wilayah pesisir menjadi modal utama dalam pengembangan usaha mencari nafkah untuk keperluan keluarganya. dari tradisi serta pola, masyarakat dalam melaksanakan aktivitas dibidang perikanan masih menggunakan alat-alat tradisional bila mereka melaut. Sehingga hal tersebut berpengaruh dengan hasil tangkapan yang kurang maksimal dan berdampak pula pada perekonomian masyarakat nelayan desa Kilensari. 
Aspek Sosial Budaya Masyarakat Desa Kilensari

Dalam perspektif stratifikasi sosial ekonomi, masyarakat nelayan di daerah pesisir. Masyarakat pesisir terbentuk oleh kelompok-kelompok sosial yang sangat beragam. Hasil penelitian kategori karakteristik sosial budaya dalam kaitan dengan dinamika proses sumberdaya ekonomi, maka masyarakat nelayan di desa Kilensari dapat dibagi atas 3 Kategori yaitu:

a. Masyarakat nelayan yang sepenuhnya menggantungkan hidupnya dilaut. secara umum didominasi oleh kaum laki-laki yang menyandang predikat sebagai kepala rumah tangga, namun ada pula beberapa wanita karena dengan kehilangan suami (meninggal) terpaksa merangkap menjadi kepala rumah tangga dan sebagai pemberi nafkah untuk keluarga sehingga mereka menggantungkan hidupnya di laut.

b. Masyarakat nelayan yang terbentuk dalam aktivitas kelompok yang melaksanakan aktivitas usahanya yang merupakan kelanjutan dari usaha yang didapat dari hasil melaut, mereka adalah para tiba-tiba, penjaja ikan, pengolah ikan dengan pengasapan dan ikan asin, bahkan membuat hasil olahan ikan untuk dijual dalam bentuk ikan masak untuk dijual di warung maupun toko.

c. Masyarakat yang menggantungkan aktivitas usahanya dengan menyediakan bentuk peralatan seperti kail, pancing, bahkan pemberi modal usaha, pemilik toko/warung, bahkan tengkulak, serta bentuk aktivitas sosial lainnya seperti Koperasi, Arisan ibu-ibu nelayan, arisan PKK dan aktivitas lainnya yang menunjang kegiatan nelayan.

Karakteristik sosial budaya tersebut diatas telah melahirkan bentuk stratifikasi sosial yang permanen. Kategori sosial kelompok nelayan tersebut adalah nelayan yang secara utuh (nelayan penuh) mencari nafkah baik siang maupun malam di laut, mereka dikatakan sebagai kelompok dan penunjang utama produksi dibidang perikanan sekaligus penyumbang pendapatan keluarga. Untuk kelompok pada point (b) merupakan bentuk paduan dari nelayan penuh dan masyarakat biasa, sedangkan untuk 
point (c) dapat dikategorikan sebagai masyarakat yang turut memberikan andil terhadap aktivitas dibidang perikanan untuk menyediakan peralatan, memberikan modal, sebagai kelompok elit di kelurahan 15 yang mampu menggerakan perekonomian masyarakat.

\section{Aspek Budaya dalam Sistem Ekonomi}

Aspek budaya yang paling tampak adalah dalam pola produksi kerajinan kayu yang tidak semata-mata urusan teknis menjadikan bongkahan kayu menjadi sepasang souvenir. Akan tetapi, pengetahuan mereka dalam membuat kerajinan kayu, seperti caranya, bentuk disain, dan motif gambar yang dipilih merupakan ranah budaya para pengrajin kerajinan kayu. Ada pewarisan pengetahuan keterampilan membuat kerajinan kayu yang berlangsung di dalam lingkungan keluarga dari generasi ke generasi. Ada proses pengadopsian teknik membatik pada motif gelang. Ada proses akulturasi dalam motif gambar pada kerajinan kayu, yakni motif ikan atau bintang laut karena pada masanya kerajinan kayu banyak digunakan oleh wisatawan. Satu lagi yang cukup menarik adalah aspek budaya yang tampak pada pola konsumsi para pengrajin kerajinan kayu. Nilai prestis atau kebanggaan atas kesuksesan dalam menjalankan usaha mereka sebagai pengrajin kerajinan kayu juga terlihat. Hal itu tampak dari kepemilikan rumah bagus berikut isinya, bahkan bisa lebih dari satu; kepemilikan mobil, yang juga bisa lebih dari satu.

Faktor-faktor pendorong perubahan sosial budaya aktivitas produksi kerajinan kayu desa Kilensari

Dalam masyarakat dimana terjadi suatu proses perubahan, terdapat faktor-faktor yang mendorong jalannya perubahan yang terjadi. Faktor-faktor tersebut antara lain sebagai berikut : 1) Kontak dengan budaya lain 2) sistem pendidikan formal yang maju 3) sikap menghargai hasil karya seseorang dan keinginan-keinginan untuk maju; 4) toleransi terhadap perbuatan-perbuatan yang menyimpang (deviation), yang bukan merupakan delik; 5) sistem terbuka lapisan masyarakat; 6) penduduk yang heterogen; 7) ketidak puasan masysarakat terhadap bidangbidang kehidupan tertentu 8) orientasi ke masa depan; 9) nilai bahwa manusia harus senantiasa berihtiar unntuk memperbaiki hidupnya (Soekanto, 2013).

Menurut Kontjaraningrat (1990), penemuan baru dalam masyarakat 
pesisir didorong oleh kreativitas yang tumbuh karena:

a. Kesadaran para individu akan adanya kekurangan-kekurangan dalam kebudayaan mereka

b. Adanya kesadaran akan pentingnya mutu keahlian yang bersangkutan, sehingga yang telah ahli dalam suatu bidang akan terus meningkatkan keahliannya

c. Adanya sistem perangsang dalam masyarakat yang mendorong mutu, seperti kehoramtan, kedudukan, harta

d. Adanya krisis dalam masyarakat, yag berarti bahwa dalam masyarakat itu ada sejumlah orang yang menentang keadaan karena mereka sadar akan kekurangan-kekurangan yang ada dalam masyarakat itu serta merasa tidak puas dengan keadaan itu (dalam Satria, 2015).

Berdasarkan hasil penelitian, ditemukan beberapa faktor yang mendorong perubahan sosial budaya pada aktivitas produksi kerajinan kayu di Desa Kilensari Kecamatan Panarukan Kabupaten Situbondo sebagai berikut:

1. Ketidakpuasan Masyarakat Terhadap Bidang-Bidang Kehidupan Tertentu Masyarakat tidak puas dengan metode lama dimana dalam hasil yang diperoleh sebagai nelayan tidak menggunakan pengaman dan baju pelindung dan hanya mengandalkan alat tradisional. Akibatnya, terjadilah human error atau kecelakaan kerja karena kesalahan manusia yang juga bedampak pada penghasilan nelayan secara ekonomi.

2. Kontak dengan budaya lain Terjadinya perubahan pada aktivitas produksi kerajinan kayu adalah karena proses difusi. Difusi merupakan penyebaran unsur-unsur kebudayaan dari individu kepada individu lainnya. Dengan terjadinya difusi, penemuan baru yang sudah diterima oleh masyarakat dapat disebarkan kepada masyarakat luas. Pada aktivitas produksi kerajinan kayu, Menurut Key Informan adalah pertama kali diajarkan oleh pendatang yang berasal dari Bali. Lalu, masyarakat desa Kilensari mengadopsi usaha baru tersebut dan dilaksanakan sampai sekarang.

\section{Orientasi Masa Depan}

Dulunya masyarakat nelayan desa Kilensari sangat menggantungkan perekonomiannya melalui hasil penangkapan ikan. Hal ini tentu saja tidak baik karena bisa saja menyebabkan terjadinya merosotnya perekonomian masyarakat pesisir desa 
Kilensari pada saat tidak ada musim ikan. Sekarang masyarakat sudah berpikir jauh kedepan bagaimana perekonomian masyarakat nelayan ini bisa tetap terus berkembang dan terjaga, sehingga keberlangsungan dari hasil aktivitas produksi kerajinan kayu bisa dinikmati oleh masyarakat kini hingga seterusnya.

4. Nilai Bahwa Manusia Harus Senantiasa Berihtiar Untuk Memperbaiki Hidupnya

$$
\text { Masyarakat Desa Kilensari }
$$

Kecamatan Panarukan punya pepatah Madura bahwa Lebbi begus gagal ben

\section{KESIMPULAN}

Aspek-aspek yang mengalami perubahan dalam aktivitas produksi kerajinan kayu pada masyarakat Desa Kilensari Kecamatan Panarukan Kabupaten Situbondo adalah aspek pengetahuan, aspek kepercayaan, aspek sosial budaya, dan aspek sistem ekonomi. Sedangkan faktor-faktor yang mendorong terjadinya perubahan adalah terjadinya kontak dengan budaya lain, ketidakpuasan Masyarakat terhadap bidang-bidang kehidu pan tertentu, orientasi masa depan dan nilai bahwa manusia harus senantiasa berihtiar untuk memperbaiki hidupnya. bengal nyobak ebendingagi th tao gagal polanah tak pernah nyobak. ini menunjukkan bahwa masyarakat senantiasa berusaha agar kehidupan mereka menjadi semakin baik dari hari ke harinya. Menjaga keamanan, menjaga keseimbangan lingkungan, menjaga keaslian produksi, menerapkan prinsip keadilan dalam pembagian hasil, menunjukkan bahwa masyarakat berihtiar dalam memperbaiki hidupnya. 
Journal of Aquaculture Science

DOI: https://doi.org/10.31093/joas.v6i1IS.174
July 2021 Vol 6 Issue Spesial: 198-207

Online pada http://joas.co.id

\section{DAFTAR PUSTAKA}

Abidin, Yusuf Zainal dan Saebani, Beni Ahmad. 2014. Pengantar Sistem Sosial Budaya di Indonesia. Bandung. CV. Pustaka Setia.

Hidir, Ahmad. 2009. Antropologi Budaya, Perpektif Ekologi dan Perubahan Budaya. Pekanbaru . Unri Press.

Nasikun. 1974. Sistem Sosial Indonesia. Jakarta. Rajawali Press.

Ritzer, George \& Smart, Barry. 2011. Handbook Teori Sosial. Bandung. Nusa Media.

Ritzer, George. 2012. Teori Sosiologi dari Sosiologi Klasik sampai Perkembangan Terakhir Postmoder. Edisi kedelapan. Yogyakarta. Pustaka Pelajar.

Satria, Arif. 2015. Pengantar Sosiologi Masyarakat Pesisir. . Jakarta. Yayasan Pustaka Obor Indonesia

Setiadi, Elly M dan Kolip, Usman. 2011. Pengantar Sosiologi, Pemahaman Fakta dan Gejala Permasalahan Sosial : Teori, Aplikasi, dan Pemecahannya. Kencana Prenada Media Group. Jakarta

Soekanto, Soerjono. 2013. Sosiologi Suatu Pengantar. Jakarta. PT. Raja Grafindo Persada.

Soemardjan, Selo dan Soemardi, Soeleman. 1974. Jakarta. Setangkai Bunga Sosiologi. Felu.

Sztompka, Piötr.2017. Sosiologi Perubahan Sosial. Jakarta. Kencana. 